\title{
EVALUATION OF GPR CAPABILITIES IN THE STUDY OF SEISMOGENIC FAULTING AND DEFORMATION IN THE BOTTOM SEDIMENTS OF LAKE UPOLOKSHA (NORTHEAST OF THE FENNOSCANDIAN SHIELD)
}

\author{
A. I. Rodionov ${ }^{1}$, S. B. Nikolaeva ${ }^{2}$, P. A. Ryazantsev ${ }^{1}$ \\ ${ }^{1}$ Institute of Geology, Karelian Research Centre of RAS, Petrozavodsk, Russia \\ ${ }^{2}$ Geological Institute, Kola Science Centre of RAS, Apatity, Russia
}

\begin{abstract}
The article describes the experience of using the GPR method to study the bottom sediments of Lake Upoloksha located in the Kola Peninsula, Russia. Such sediments are viewed as good archives of various Holocene geodynamic processes, including tectonic and paleoseismic events. This small lake is located in the zone of the active NWstriking lineament, which length is more than $20 \mathrm{~km}$. A series of asars (eskers) stretches along the lineament. In the previous studies, the bottom sediments of the lake were investigated by geological methods, including core sampling, lithological and micro-palaeontological analysis of sediments. The studies have revealed a horizon which features are indicative of catastrophic changes in the sedimentation conditions due to a single impact. Our study aimed at evaluating the level of informativeness of the GPR method for detecting disturbances in the bottom sediments and new paleoseismic dislocations. The study referred to the hypothesis of the distribution of seismic foci in the Kola Peninsula in the Holocene. A ground-penetrating radar OKO-2 and an antenna unit (150 MHz) were used to survey of Lake Upoloksha in detail. The positions of the main stratigraphic horizons of the bottom sediments were clarified, and their thicknesses were measured more precisely. The GPR measurement error in comparison to the drilling data did not exceed $\pm 0.2 \mathrm{~m}$, which corresponds to the resolution of the antenna used in the survey. The GPR data confirmed the existence of seismic dislocations identified by the geological methods and discovered new zones of displacement and deformation in the organogenic and mineral bottom sediments. The survey detected vertical displacements, which amplitudes vary from 1.3 to $1.7 \mathrm{~m}$, and landslides caused by seismogravitational rock collapse. Based on the GPR data, a bathymetric map was constructed. It shows the positions of the two basins of Lake Upoloksha. The survey provided the basis for a model showing the isosurface of the top of the mineragenous sequence. In the central part of the mineral-base model, there is a series of individual stepwise blocks of the sublatitudinal strike, which result from seismic movements. The GPR survey of Lake Upoloksha demonstrates that the GPR method can be successfully applied to estimate the mineral and organogenic parts of the bottom sediments, study their lithostratigraphic features, and detect changes in the structure of the bottom sediments. Based on the GPR data, it becomes possible to map even the small-scale disturbances.
\end{abstract}

Key words: ground penetrating radar; radar profiles; bottom-sediments; seismic faults; Holocene; neotectonics; Kola Peninsula

RESEARCH ARTICLE

Received: June 4, 2018

Revised: August 31, 2018

Accepted: September 21, 2018

For citation: Rodionov A.I., Nikolaeva S.B., Ryazantsev P.A., 2018. Evaluation of GPR capabilities in the study of seismogenic faulting and deformation in the bottom sediments of Lake Upoloksha (northeast of the Fennoscandian shield). Geodynamics \& Tectonophysics 9 (4), 1189-1203. doi:10.5800/GT-2018-9-4-0390.

Для цитирования: Родионов А.И., Николаева С.Б., Рязанцев П.А. Оценка возможностей георадиолокации при изучении сейсмогенных нарушений и деформаций в донных осадках (на примере озера Уполокшское, северо-восток Фенноскандинавского щита) // Геодинамика и тектонофизика. 2018. Т. 9. № 4. С. 1189-1203. doi:10.5800/GT-2018-9-4-0390. 


\title{
ОЦЕНКА ВОЗМОЖНОСТЕЙ ГЕОРАДИОЛОКАЦИИ ПРИ ИЗУЧЕНИИ СЕЙСМОГЕННЫХ НАРУШЕНИЙ И ДЕФОРМАЦИЙ В ДОННЫХ ОСАДКАХ (НА ПРИМЕРЕ ОЗЕРА УПОЛОКШСКОЕ, СЕВЕРО-ВОСТОК ФЕННОСКАНДИНАВСКОГО ЩИТА)
}

\author{
А. И. Родионовㅁ, С. Б. Николаева², П. А. Рязанцев ${ }^{1}$ \\ 1 Институт геологии КарНЦ РАН, Петрозаводск, Россия \\ 2 Геологический институт КНЦ РАН, Апатиты, Россия
}

\begin{abstract}
Аннотация: В статье рассматривается опыт применения метода георадиолокации для изучения донных осадков водоемов, которые являются хорошими архивами различных геодинамических процессов голоцена, в том числе тектонических и палеосейсмических. Объектом изучения было малое озеро Уполокшское, расположенное на территории Кольского полуострова. Оно приурочено к зоне активного линеамента северозападного простирания, протяженностью более 20 км, вдоль которого вытянута серия озовых гряд. Предшествующими исследованиями донные отложения озера изучались геологическими методами, в числе которых отбор керна, литологический и микропалеонтологический анализ осадков. В результате был выделен горизонт, обладающий признаками, которые указывают на катастрофические изменения условий осадконакопления вследствие одномоментного воздействия. Цель представленной работы - оценка уровня информативности георадиолокации при выявлении нарушений в донных осадках, а также поиск и изучение новых палеосеймодислокаций в рамках существующей гипотезы о распределении очагов сейсмической активности на Кольском полуострове в голоцене. Для этого при помощи георадара ОКО-2 с антенным блоком 150 МГц выполнена детальная съемка котловины озера Уполокшское, что позволило уточнить мощность и проследить положение главных стратиграфических горизонтов донных отложений, установленных ранее. Погрешность результатов георадиолокации при сопоставлении с данными бурения не превысила \pm 0.2 м, что соотносится с разрешающей способностью используемой антенны. В ходе исследования по данным георадиолокации подтверждено существование сейсмодислокаций, выявленных геологическими методами, а также обнаружены новые области смещения и деформации органогенных и минерагенных донных осадков. К таким объектам относятся вертикальные смещения с амплитудой от 1.3 до 1.7 м, а также оползневые тела, вызванные сейсмогравитационными обвалами. Помимо этого, по результатам работ была построена батиметрическая карта, по которой определено положение двух котловин озера, и модель изоповерхности кровли минерагенной толщи. В центральной части модели минерального основания наблюдается ряд отдельных ступенчатых блоков субширотного простирания, сформированных в результате сейсмических подвижек. В результате исследований на примере озера Уполокшское показано, что метод георадиолокации позволяет оценить минеральную и органогенную часть донных отложений и изучить их литостратиграфические особенности, а также выделить изменение структуры залегания донных осадков. При этом были закартированы даже мелкомасштабные нарушения.
\end{abstract}

Ключевые слова: георадиолокация; радарограмма; донные осадки; голоцен; сейсмодислокация; неотектоника; Кольский полуостров

\section{1. ВВЕДЕНИЕ}

В настоящее время активно развиваются методы малоглубинной геофизики. Их применение позволяет оценить строение и состав верхней части геологического разреза на качественном уровне. Одним из широко применяемых методов для решения задач четвертичной геологии является георадиолокация. Ее использование позволяет картировать четвертичные отложения с высокой разрешающей способностью, что дает возможнось фиксировать в волновом поле не только литологиче- ские границы, но и структурную неоднородность грунтов [Neal, 2004]. Как показывает ряд исследований, с помощью георадиолокации можно уверенно выделять различные локальные неоднородности грунтов, такие как изменение крупности и сортировки [Bayer et al., 2011], внутренняя слоистость отложений [Weill et al., 2012], наличие разрывных нарушений [McClymont et al., 2008, 2010].

Перспективным направлением для использования георадиолокации является поиск различных нарушений и деформаций (в том числе и сейсмодислокаций), так как зачастую локализация таких 
объектов при помощи геологических выработок требует больших трудозатрат. Георадиолокация обеспечивает непрерывное сканирование изучаемой толщи, что позволяет не только определить местоположение нарушения, но и изучить его параметры [Dentith et al., 2010; Lunina et al., 2018; Taraban'ko, 2007]. В мировой практике этот геофизический метод стал фактически стандартным при проведении различных видов геологических исследований, в том числе при изучении стратиграфии рыхлых осадочных отложений [Reicheret, Reiss, 2001; Neal, 2004; Tamura et al., 2008]. Применяется он и для решения задач палеосейсмологии [McCalpin, 2009; Lunina et al., 2015].

Следует отметить, что использование георадара в палеосейсмологии является все еще новым и не до конца проработанным способом повышения эффективности работ. Однако в комплексе с другими геолого-геоморфологическими методами и подходами георадиолокация значительно повышает общую информативность и расширяет возможности исследований [Meyers et al., 1996; Schwamborn et al., 2002; Tronicke et al., 2006; Sambuelli, Bava, 2012; u дp.].

Изучаемый объект расположен на территории Фенноскандинавского щита, который характеризуется слабым уровнем современной сейсмической активности [Malovichko et al., 2007]. При этом изучение палеосейсмодислокаций в его пределах имеет важное научное значение при решении фундаментальных задач геодинамики и неотектоники, что отражено в публикациях [Lagerbäck, 1990; Lukashov, 1995; Lukashov, Rukosuev, 1997; Nikolaeva, 2001; Mörner, 2004; Shitov et al., 2010; Nikolaeva et al., 2016b, 2017]. Существуют примеры успешного применения георадиолокации и для решения проблем четвертичной геологии Фенноскандии - выделения гляциотектонических деформаций в гляциофлювиальных отложениях Западной Финляндии [Pasanen, 2009].

Цель данного исследования - оценить возможности георадиолокации при поиске нарушений и деформаций, в том числе и сейсмодислокаций в донных отложениях (ДО) озерной котловины, расположенной на юго-западе Кольского региона на западном побережье озера Имандра (рис. 1). При этом решались попутные задачи определения границ между различными генетическими типами осадков и подтверждения участков нарушений, выявленных геологическими методами. Выполнено уточнение характера рельефа дна озера и мощности литологических разновидностей До.

Интерес к использованию новых методов для выделения сейсмодислокаций и других катастрофических явлений в ДО озер обусловлен необходимостью обеспечения экологической безопасности и рационального природопользования Мурманской области - региона с широко развитым горнопромышленным кластером и объектами атомной энергетики (Кольская АЭС). В то же время локализация и возрастные привязки сейсмодислокаций имеют важное значение для оценки геодинамического режима территорий, а также считаются индикаторами для выявления зон активных разломов.

\section{2. МЕТОДЫ ИССЛЕДОВАНИЯ}

Метод георадиолокации основан на генерации георадаром сверхширокополосных электромагнитных импульсов наносекундного диапазона и приеме сигналов, отраженных от неоднородностей изучаемой среды. Этот метод активно развивается с 80-х годов XX в., и его основы изложены в ряде монографий [Vladov, Starovoitov, 2004; Daniels, 2004; Jol, 2009]. Принципы его работы во многом схожи с классической сейсморазведкой. В геологическую среду передается импульс (в данном случае электромагнитная волна), а через определенный промежуток времени регистрируются его отражения. Принимаемый сигнал несет в себе информацию об электрофизических неоднородностях среды и записывается в виде трассы, которая имеет ряд параметров - время прихода, амплитуду, фазу. Набор трасс формирует радарограмму, где экстремумы одних и тех же фаз соединены между собой условными линиями - осями синфазности. Как правило, наличие осей синфазности свидетельствует о формировании рефлекторов из-за изменения электрофизических свойств среды. Это позволяет выделять отдельные слои, которые можно сопоставлять с геологическим строением исследуемой толщи. Кроме осей синфазности, в качестве поисковых признаков выступают участки записи с определенными параметрами волнового поля - так называемые георадарные комплексы и фации [Vladov, Starovoitov, 2004]. Таким образом, объект поиска на радарограмме может иметь комплексные характеристики, такие как наличие осей синфазности определенной формы, амплитуда отраженного сигнала и его затухание и т.д. Совокупность этих признаков формирует так называемый поисковый образ, который служит инструментом интерпретации [Overgaard, Jakobsen, 2001; Jakobsen, Overgaard, 2002]. К примеру, в монографии [Last, Smol, 2001], в главе, посвященной использованию георадиолокации в палеолимнологии, приведено восемь таких образов.

Изначально на радарограмме по горизонтальной оси указывается положение зондирующих трасс, а по вертикальной - время прихода импульсов. Переход от временной разверстки к глубин- 

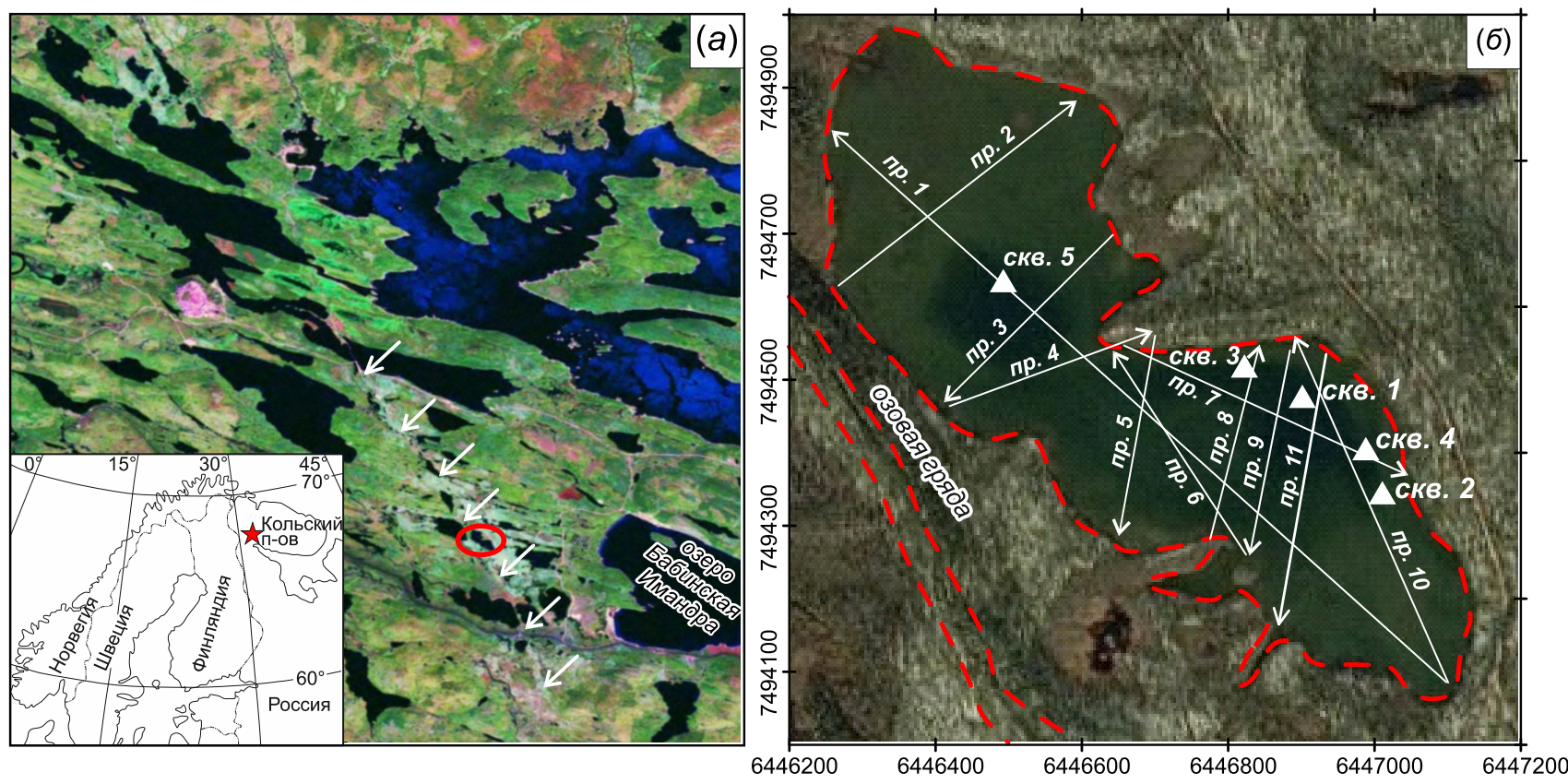

Рис. 1. Карта расположения озера Уполокшское $(a)$ и схема георадарных профилей в пределах изученной озерной котловины (б). На рис. а стрелками показано разрывное нарушение, звездочкой и кружком - местоположение изученной озерной котловины в зоне разлома. На рис. б черными треугольниками показаны скважины.

Fig. 1. The map showing the location of Lake Upoloksha( $a$ ). Arrows show faults; the asterisk and the circle mark the location of the studied lake basin in the fault zone. The scheme of GPR profiles in the studied lake basin. Black triangles show drilled holes (б).

ному разрезу выполняется путем присвоения диэлектрической проницаемости $(\varepsilon)$ выделенным слоям. Это позволяет получить скорость распространения волны и, зная время, рассчитать глубину залегания границ. Значение $\varepsilon$ определяется при анализе дифрагированной волны, которая формируется над локальными объектами либо на участках со значительным контрастом $\varepsilon$. Параметр $\varepsilon$ также устанавливается в ходе параметрических лабораторных наблюдений. Следует отметить, что величина $\varepsilon$ является комплексной и зависит от множества факторов.

В георадиолокации помимо диэлектрической проницаемости важным параметром является электрическая проводимость среды, которая зависит от литологического состава пород, а также от количества и минерализации воды и определяет удельное затухание сигнала (от него зависит максимальная глубина исследования). Особенное значение имеет учет электропроводности при выполнении георадиолокационных работ на акватории. Среди аппаратурных характеристик, влияющих на детальность и глубинность исследования, ключевую роль играет центральная рабочая частота антенного блока. Чем выше этот параметр, тем большую вертикальную разрешающую способность обеспечит метод. С уменьшением этого параметра разрешающая способность уменьшится, однако возрастет глубинность.

Традиционным методом геофизического изучения водоемов является сейсмоакустическое профилирование. В литературе есть множество примеров, где на основе данных, полученных с помощью сейсмоакустики, строились весьма подробные разрезы донных отложений [Shalaeva, Starovoitov, 2010], а также выделялись следы тектонических нарушений в минерагенных осадках донных отложений озер [Smith et al., 2017]. Однако необходимо учитывать меньшую вертикальную разрешающую способность и большую чувствительность сейсмоакустического профилирования к наличию водорослей в сравнении с методом георадиолокации [Kovacs, 1991]. Этот факт может быть важным при выборе средств для изучения малоглубинных водоемов и комплексов маломощных донных осадков.

Направление по использованию георадиолокации для исследования малоглубинных акваторий активно развивалось со второй половины XX в. и прошло путь от весьма сложного в исполнении и интерпретации метода до современной и высокоинформативной технологии. На сегодняшний день применение георадара для решения задач при работе на акваториях распространено достаточно широко. Так, например, наглядно показано изуче- 
ние донных осадков ледникового озера в статье [Sambuelli, Bava, 2012], в которой на основе информации георадиолокации построены батиметрические карты. После сопоставления с результатами бурения авторы отмечают высокую точность георадарного определения кровли донных осадков. Работа интересна тем, что в ней проводится учет физических свойств воды и их влияние на электромагнитный сигнал. Схожие исследования проводились и для речных отложений [Sambuelli et al., 2009], где помимо свойств воды учитывалось влияние петрофизических особенностей слоев, слагающих толщу донных осадков.

Как уже отмечалось, специфической чертой работы методом георадиолокации на акваториях является наличие водной толщи. Электропроводимость воды сказывается как на глубинности исследований, так и на количестве регистрируемых шумов [Vladov, Pyatilova, 2009], меняются также и спектральные характеристики сигнала [Omelyanenko, Khristoforov, 2012]. Важным фактом для проводимых работ являются практические наблюдения, показавшие, что озера, расположенные в пределах Фенноскандии, имеют оптимальные условия для применения георадара [Starovoytov et al., 2016]. Это связано с малой минерализацией воды и, как следствие, с малым затуханием электромагнитной волны, что позволяет получать полезный сигнал на поздних временах с малым уровнем помех.

По итогу анализа литературных источников, связанных с георадиолокационным изучением малых водоемов, можно заключить, что методика обработки и интерпретации данных, а также общая тенденция построения задач и их решения схожи с изысканиями, выполняемыми на суше. Однако исследования по выделению тектонических нарушений, которые широко проводятся при наземных исследованиях [Fisher et al., 1995; Busby, Merritt, 1999; Jakobsen, Overgaard, 2002; Gross et al., 2003; Christie et al., 2009; Ercoli et al., 2013, 2014; Bubeck et al., 2015], на водоемах представлены крайне ограниченно.

\section{3. ОБЪЕКТ ИССЛЕДОВАНИЯ}

Объектом исследования является озеро Уполокшское с высотной отметкой 133.4 м над уровнем моря, расположенное на западном побережье субширотной (Бабинской) ветви самого крупного водоема Кольского региона - озера Имандра (рис. 1). Котловина озера имеет вытянутую на 1.2 км форму при ширине 0.3-0.5 км и расположена в зоне новейшего линеамента северо-западного простирания, общей протяженностью около 20 км. Берега озера песчано-каменистые, частично заболоченные. По обе стороны от котловины проходят протяженные озовые гряды.

Эта территория входит в состав Беломорского геоблока (террейна), сложенного в основном метаморфизованными докембрийскими породами кристаллического фундамента. В районе расположения озера под чехлом четвертичных отложений, представленных различными моренами, флювиогляциальными и лимногляциальными осадками, залегают преимущественно гнейсы комплекса основания (биотитовые, амфибол- и пироксен-биотитовые), мигматиты, амфиболиты и основные вулканиты [Mitrofanov, 2001].

Территория Кольского региона неоднократно подвергалась оледенениям, последним из которых было Валдайское. Изученная озерная котловина расположена в 45-50 км к западу от внешней полосы самого молодого пояса краевых маргинальных образований Кольского региона [Evzerov, Nikolaeva, 2000]. Рельеф района, примыкающего к западному побережью Имандры, представлен в основном болотистыми пространствами и многочисленными озерами, часто с вытянутой формой котловин, обусловленной направлением движения ледников последнего оледенения вдоль господствующих тектонических разломов.

Донные осадки озера Уполокшское были детально изучены ранее при помощи традиционных геологических подходов, включающих бурение скважин, литологический и микропалеонтологический анализ осадков [Nikolaeva et al., 2016a, 2017]. Литологическое изучение кернов пяти скважин показало, что котловина озера заполнена разнозернистым песком, подстилающим слой алеврита, сменяющегося вверх по разрезу пресноводной гиттией (сапропелем). В толще гиттии резко выделяется аномальный горизонт, состоящий из обломков пород разной формы, цвета и размеров, органического материала, торфа, песка, обломков древесины и других растительных остатков, заключенных в сапропелевую матрицу. Присутствие в разрезах озер аномального («брекчиевого» или «маркирующего») горизонта явно указывает на катастрофические изменения условий осадконакопления. Судя по характеру нарушений, образование осадков было быстрым, одномоментным, что возможно только в результате сильного встряхивания во время землетрясения и связывается с сейсмогравитационными оползневыми процессами. По данным бурения размер оползневого тела $600 \times 50$ м. Радиоуглеродное датирование образца гиттии из горизонта ненарушенных осадков, подстилающих «брекчиевый» горизонт, и обломок древесины из его верхней части свидетельствуют об образовании этих осадков в интервале времени 6.5-5.6 тыс.л.н. (радиоуглеродных) или 6.47.3 тыс. л.н. (кал.) [Nikolaeva et al., 2016a, 2017]. 

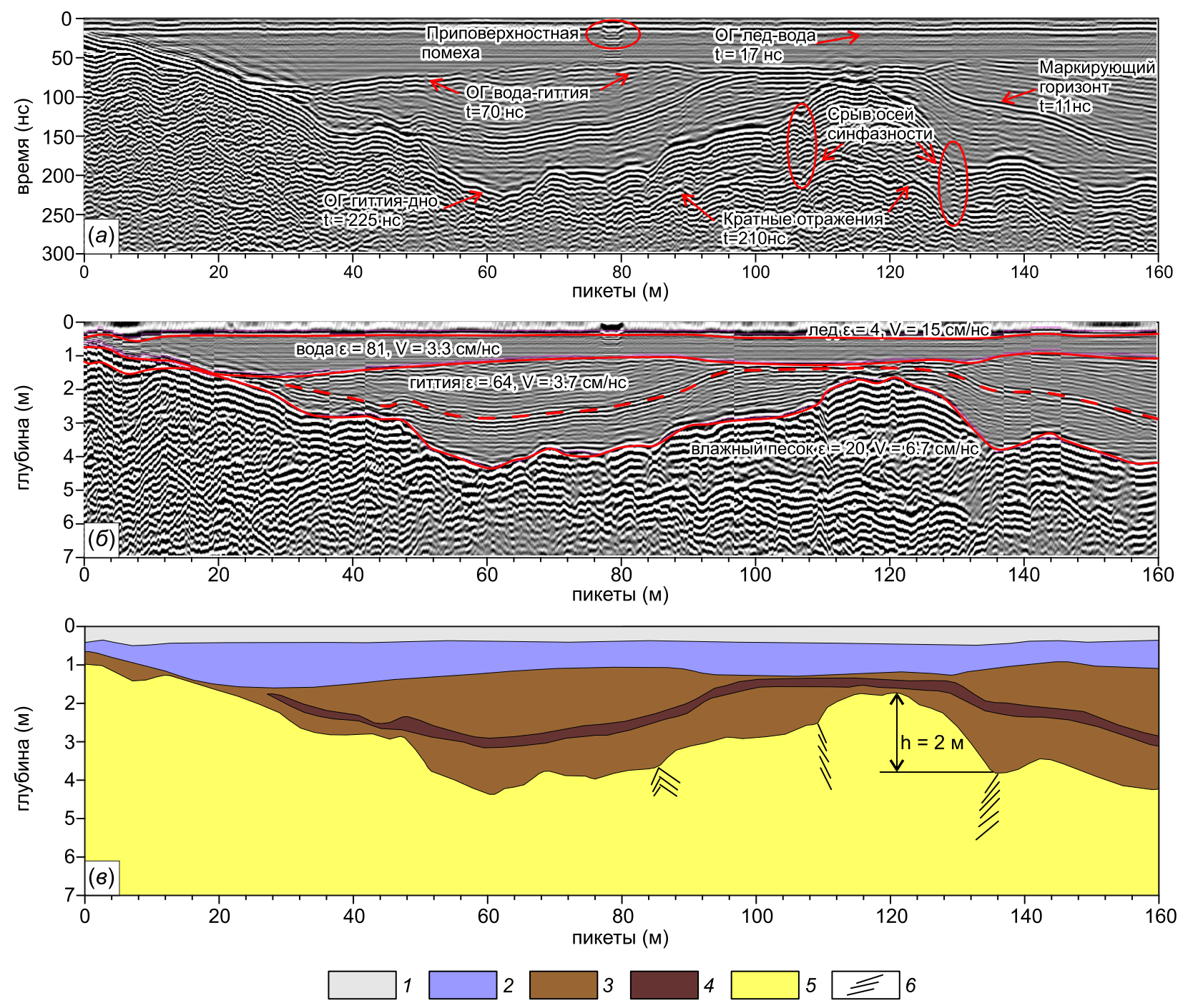

Рис. 2. Профиль георадиолокации 6 с временной разверсткой 300 нс $(a)$, пересчитанный в глубинный после ввода є (б) и результаты интерпретации (в), где: 1 - лед; 2 - вода; 3 - гиттия; 4 - маркирующий горизонт; 5 - пески; 6 - области смещения.

Fig. 2. GPR profile 6 (time time-base sweep of $300 \mathrm{~ns}$ ) (a), converted to depth after input $\varepsilon$ (б). Interpretation results: 1 ice; 2 - water; 3 - gyttja; 4 - marking horizon; 5 - sands; 6 - areas of displacement ( 8 ).

\section{4. ПОЛУЧЕННЫЕ РЕЗУЛЬТАТЫ}

Для исследования ДО водоема было выполнено 11 георадарных профилей по льду, общей длиной порядка 4 пог. км, при площади озера 0.33 км² (рис. 1). Профили были заложены по нерегулярной сети и сконцентрированы в области расположения геологических скважин [Nikolaeva et al., 2016a]. Съемка осуществлялась георадаром ОКО-2 с антенным блоком АБ 150М (центральная частота 150 МГц, заявленная вертикальная разрешающая способность \pm 0.3 м). Шаг зондирования составлял 70 мм, временная разверстка до 800 нс. Регистрация и обработка данных осуществлялись в программе GeoScan32. Помимо георадиолокации, при помощи кондуктометра СОМ-100 была определена электро- проводность воды, составившая 18 мкСм/см при общей минерализации $7.9 \mathrm{ppm}$. Подобные низкие значения свидетельствуют о пригодности выбранного озера для изучения методом георадиолокации. Также оценивалась толщина льда, она варьируется в интервале от 0.5 до 0.7 м.

В качестве примера регистрируемых данных на рис. 2 приводится схема интерпретации радарограммы по профилю № 6. На первом этапе изучается временной разрез (рис. 2, a), так как при работе со льда зачастую возникает ряд интенсивных помех. Для улучшения данных выполнялась частотная фильтрация записи. Анализ радарограммы позволил выделить оси синфазности и времена прихода сигнала для четырех основных отражающих границ (ОГ), которые можно соотнести с граница- 
ми: лед - вода, вода - гиттия, гиттия - минеральное основание, а также характерный горизонт в толще гиттии, который рассматривается как маркирующий. Этот горизонт, как уже отмечалось, сложен смесью разных пород, что создает разность электрофизических свойств, вызывающих формирование интенсивного рефлектора. При анализе важно учитывать отношение вертикального масштаба к горизонтальному [Starovoitov, 2008]. Например, для представленной радарограммы соотношение было 1:10, в результате, с одной стороны, это упростило восприятие, а с другой - привело к визуальному искажению определяемых границ.

В интервале между ОГ определены георадарные комплексы, отражающие вещественный состав слоев. Например, в воде отсутствуют оси синфазности внутри слоя, а гиттия характеризуется наличием субпараллельных протяженных осей. Минеральное основание имеет более сложную георадарную картину - бугристую неоднородную структуру записи с фрагментами протяженных осей синфазности, участками дифрагированных волн и областями затухания. Это позволяет предположить наличие песков разной крупности и формы залегания. Кроме того, на записях фиксировались области срыва протяженных осей синфазности как возможные признаки дислокаций, а также наиболее проявленные волны-помехи.

На втором этапе выполняется переход к глубинному разрезу путем пикирования выделенных слоев и присвоения им параметра $\varepsilon$ (рис. 2, б), что позволило определить скорость электромагнитной волны и рассчитать глубину залегания каждого слоя. В данном случае для льда и воды использовались справочные значения $\varepsilon$, а для гиттии и подстилающего ее песка величина $\varepsilon$ определялась по набору дифрагированных волн. Льду было присвоено значение $\varepsilon=4$, воде - $\varepsilon=81$. Величина $\varepsilon$ для гиттии составила 64 , а для минерального основания $\varepsilon=20$.

В результате, трассировано положение границ каждого слоя и составлен геологический разрез (рис. 2, в). По полученным данным установлена мощность гиттии и оценено изменение конфигурации маркирующего горизонта, локализована область тектонических нарушений в минеральных осадках с амплитудой 1.2-1.7 м.

Поскольку интерпретация данных георадиолокации не всегда однозначна, в статье приводятся результаты комплексного подхода, где информация, полученная с помощью георадара, сравнивается и заверяется данными детального бурения и литостратиграфического изучения осадков, а также геоморфологическими наблюдениями из близлежащих наземных территорий, которые были опубликованы ранее [Nikolaeva et al., 2017]. Профили георадиолокации привязывались по координатам к скважинам, что позволило сравнить фрагменты радарограмм и литостратиграфические колонки (рис. 3).

Как показало сопоставление стратиграфических колонок и радарограмм, георадиолокация обеспечивает достаточно точное выделение структурных единиц разреза. Для скважин 1, 2, 3 погрешность определения границ составила не более 0.2 м, что с учетом заявленной разрешающей способности используемого антенного блока $150 \mathrm{M} \pm 0.3$ м является приемлемой величиной. Для скважин 4 и 5 наблюдается большее расхождение при локализации границы вода - гиттия, которое достигает 0.3-0.4 м. Такое несовпадение может быть обусловлено переходным типом контакта, когда взвесеподобная гиттия постепенно уплотняется и консолидируется. В результате на радарограмме формируется набор рефлекторов вместо конкретной границы раздела. Что касается алеврита, показанного в колонках, его мощность не превышает 0.1 м поэтому выделить его как отдельный слой не представляется возможным.

Дополнительным фактом, подтверждающим информативность метода георадиолокации, является обнаружение аномальных областей. Скважина 2 вскрывает толщу песка с включенными в нее фрагментами гиттии, отражающуюся на радарограмме локальной областью, ограниченной интенсивными осями синфазности. В скважине 4 установлено раздвоение маркирующего горизонта, так как мощность гиттии, разделяющей его части, составляет 0.1 м. Эта область на георадарной записи отражается как высокоинтенсивная пачка осей синфазности.

\section{5. ОБСУЖДЕНИЕ РЕЗУЛЬТАТОВ}

В результате детального анализа полученных радарограмм был выявлен ряд представительных георадарных образов, отражающих различные геологические обстановки (рис. 4). На профиле 7 и 10 выделяются оползневые тела, образованные в результате сейсмогравитационных обвалов минерального основания склонов озерной котловины (главным образом песка). Подобные нарушения хорошо картируются по интенсивным осям синфазности, что обусловлено электрофизическим контрастом переотложенного песка в сравнении с вмещающей гиттией. Этот факт может указывать на наличие сейсмического события, в результате которого произошло оползание песка из латеральной части минерального основания и дальнейшее его погружение в слой гиттии. Важно отметить, что благодаря использованию георадара можно не только определить наличие обвала, но и по его 

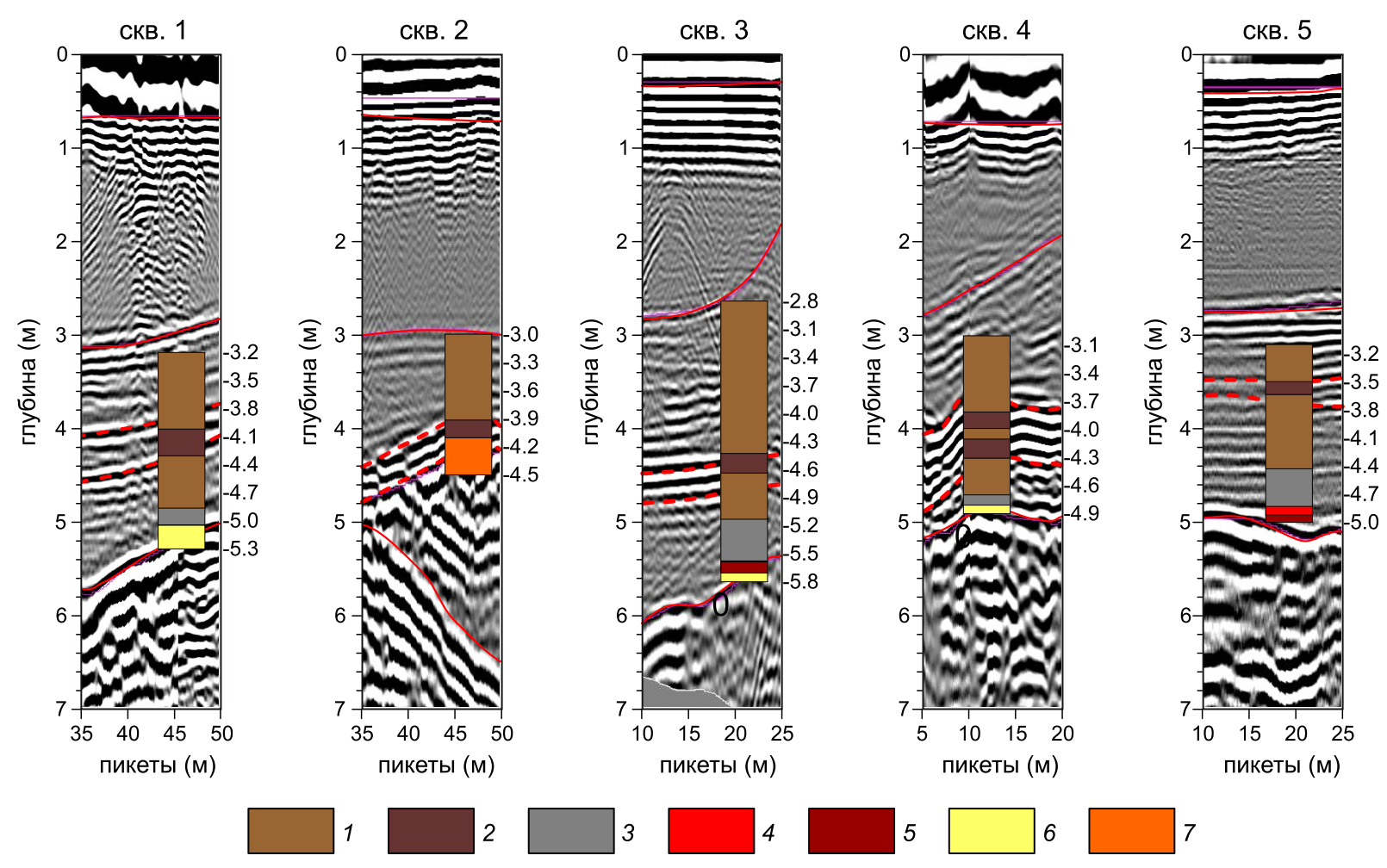

Рис. 3. Сопоставление фрагментов радарограмм и литостратиграфических колонок кернов донных отложений по работе [Nikolaeva et al., 2016a]. 1 - гиттия коричневого цвета; 2 - брекчиевый (маркерный) горизонт; 3 - гиттия черного цвета; 4 - гиттия с алевритом; 5 - алеврит; 6 - песок; 7 - песок с прослоями гиттии и алеврита.

Fig. 3. Comparison of the fragments of radarograms and the lithostratigraphic columns of the bottom sediment cores after [Nikolaeva et al., 2016a]. 1 - brown gyttja; 2 - breccia (marker) horizon; 3 - black gyttja; 4 - gyttja with silt; 5 - aleurite; 6 sand; 7 - sand with interbedded gyttja and silt.

форме предположить условия возникновения. Так, в первом случае (профиль 10) переотложение осадков происходило постепенно под действием сейсмических процессов в северо-западном направлении. Об этом свидетельствует форма аномального участка - пологая в левой части записи и относительно крутая в правой. Второй случай (профиль 7) можно рассматривать как обвал, произошедший вследствие вертикальных смещений. Этот процесс выражен в морфологии минерального основания, форме аномальной области и срыве осей синфазности, что отражает наличие сдвиговой зоны.

Кроме того, георадиолокация позволяет определять сдвиговые деформации, которые проявляются в поднятии минерального основания озера, а также в виде разрыва и смещения маркирующего горизонта. На профилях 1 и 6 (рис. 4) отчетливые границы слоев нарушены резкими перегибами и разрывами. Возникновение подобных деформаций приводит к формированию на радарограммах прерывистых осей синфазности с искаженной геометрией в сравнении с ненарушенными участками. Кроме того, области разрывов характеризуются наличием локальных участков существенного зату- хания сигнала, вызванного влиянием глинистого заполнителя зон деструкции пород. На профиле 1 показано вертикальное смещение толщи песков в придонной части озера типа сброса на величину H=1.2 м, что отражено в морфологии границы, амплитудном опускании маркирующего горизонта и изменении характера волнового поля. Профиль 6, в свою очередь, демонстрирует взбросовое смещение, в результате чего произошло образование микроразрывов по краям поднятого участка и перемещение маркирующего горизонта вверх.

На рисунке 5 демонстрируется, как отражаются указанные выше деформации в структуре профиля 6 (рис. 5, a) и профиля 7 (рис. 5, б). Протяженность деформаций составляет в среднем 20-50 м и мощность - 1-2 м. Наибольшее количество признаков нарушений было выделено в восточной части озеpa.

Обобщение всех полученных профилей георадиолокации в единой системе позволило получить карты донных отложений исследуемого озера. На батиметрической карте (рис. 6, a) выделяется вытянутая озерная котловина северо-западного простирания, которая, вероятно, была связана с до- 

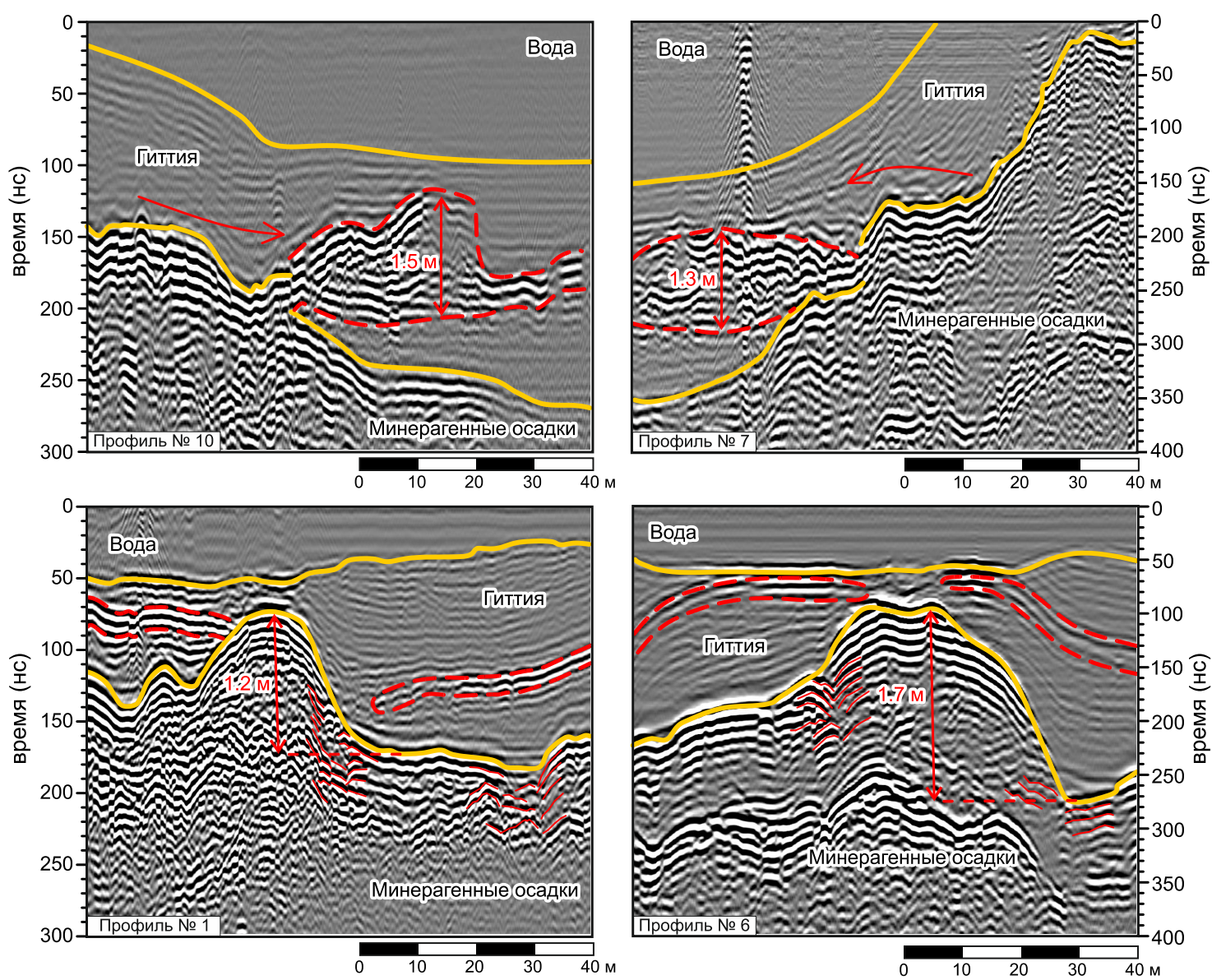

Рис. 4. Георадарные образы, отражающие нарушения в донных осадках озера, по фрагментам профилей № 1, 6, 7, 10.

Fig. 4. GPR images showing faulting in the bottom sediments of Lake Upoloksha, according to fragments of profiles No. 1, 6, 7 , and 10 .
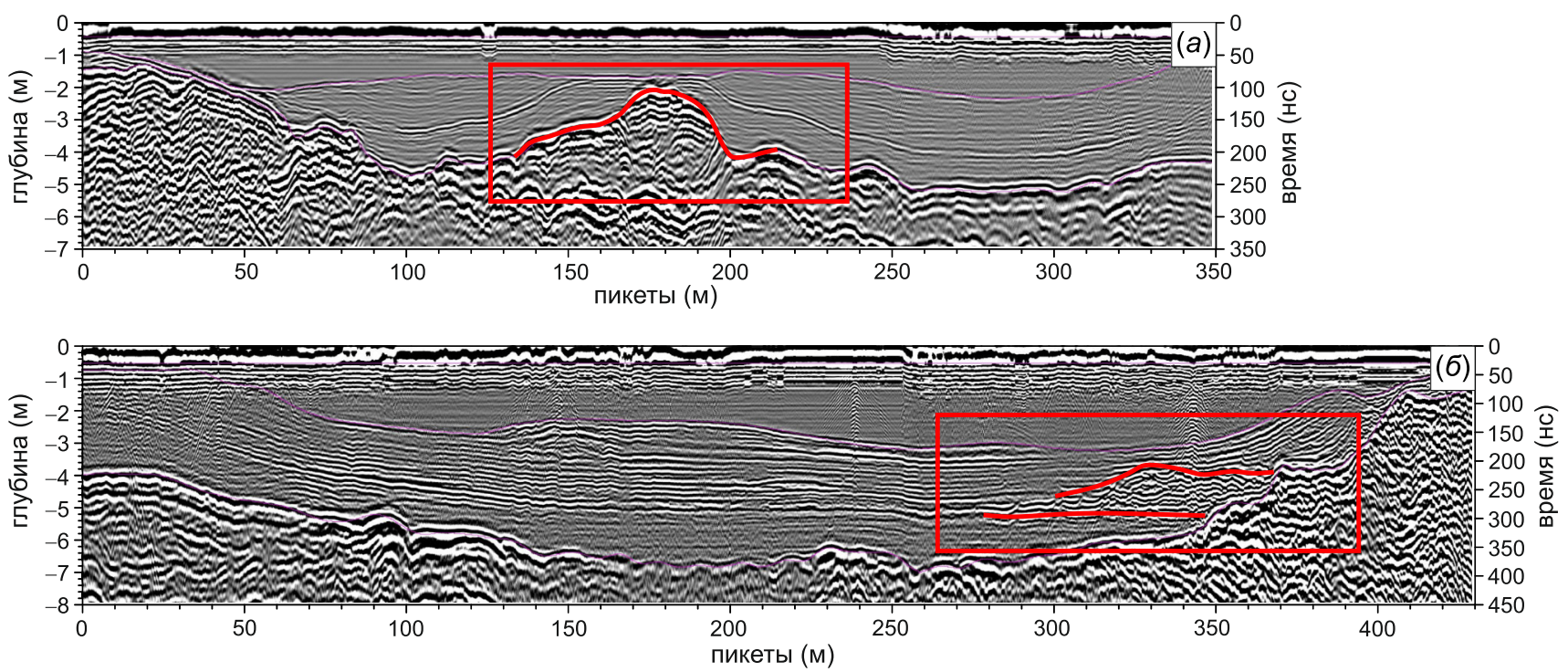

Рис. 5. Радарограммы по профилям 6 (a) и 7 (б), на которых выделенные фрагменты показывают аномальные участки и нарушения в осадконакоплении.

Fig. 5. Radarograms for profiles $6(a)$ and 7 (б). The highlighted fragments show anomalous sites and faulting in the sediments. 

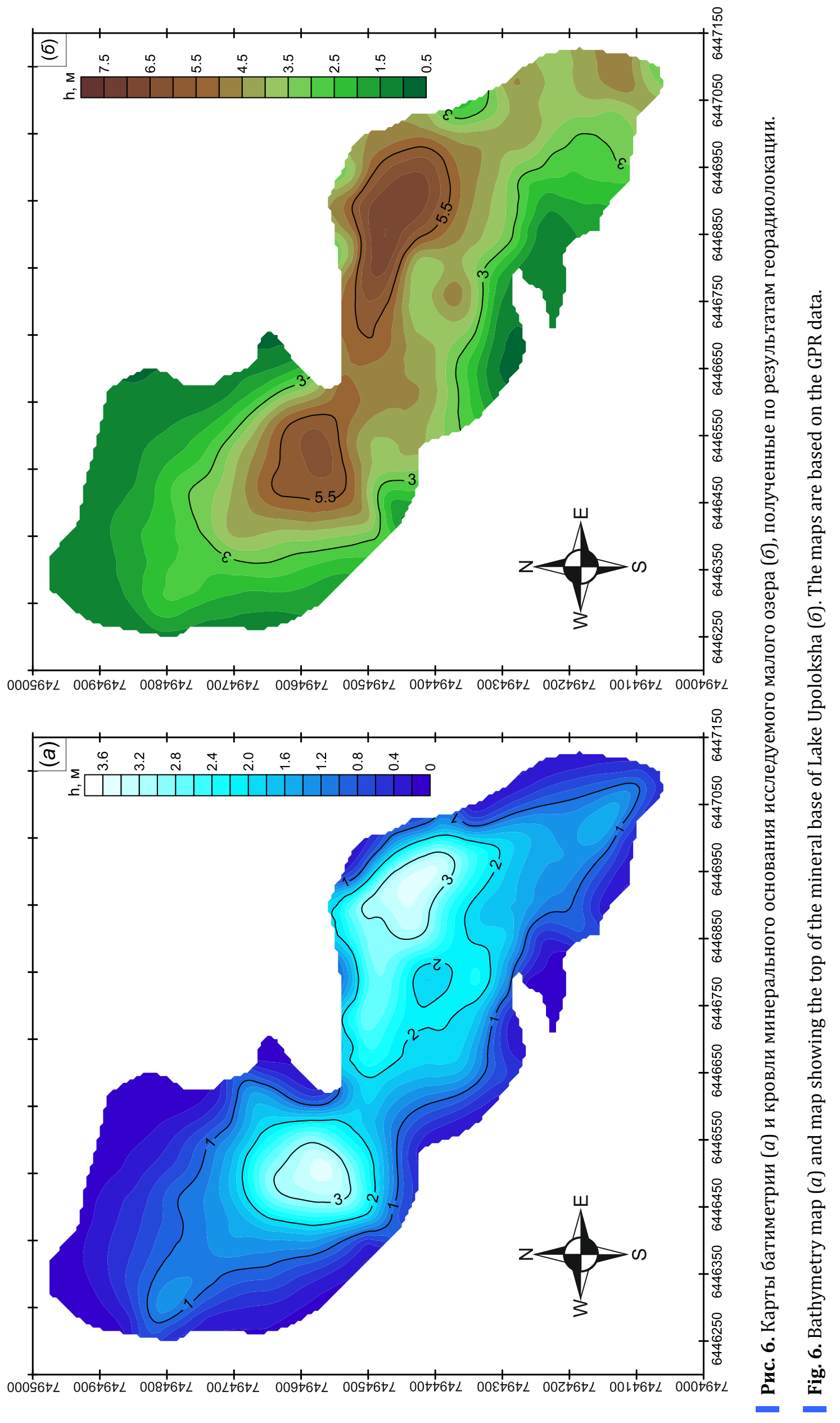


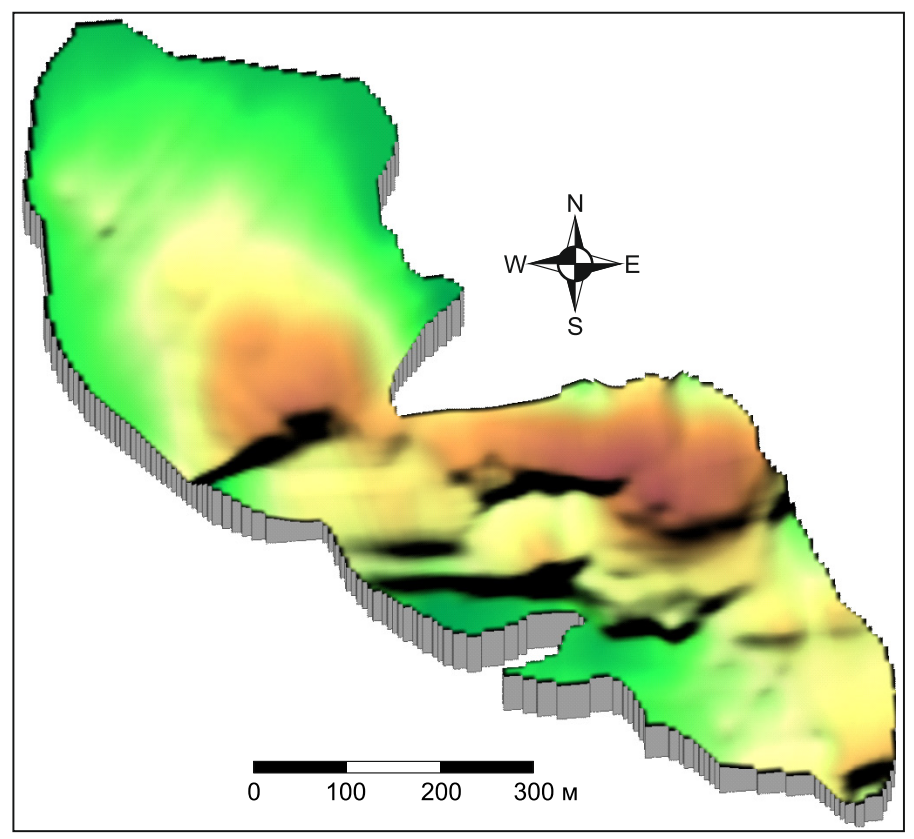

Рис. 7. Модель изоповерхности минерального основания озера.

Fig. 7. Model showing the isosurface of the mineral base of Lake Upoloksha.

ледниковой разломной зоной. В ее пределах установлены две отдельных малых котловины с глубинами более 3 м, разделенные локальным поднятием, вероятно сформированные тектоническими движениями более позднего времени. На это указывают и полученные даты фиксируемых ранее нарушений, показавшие среднеголоценовый возраст [Nikolaeva et al., 2016a].

Карта, отражающая морфологию кровли минерального основания (рис. 6, б), в общих чертах повторяет контуры понижений, выявленных по батиметрии. При этом видно, что две малых котловины (западная и восточная), достигающие глубины более 5.5 м, также были разделены локальным поднятием пород.

Так как для выделения различного рода нарушений важно не только знать глубинные отметки, но и представлять морфологию поверхности, градиент изменения глубин и т.д., была построена модель изоповерхности минерального основания озера (рис. 7). На этой модели можно видеть, что восточная часть озера характеризуется большей глубиной и неоднородностью. Кроме того, в ее центре наблюдается ряд отдельных ступенчатых блоков субширотного и северо-восточного простирания, которые, вероятно, сформированы в результате нескольких (во всяком случае не менее двух) тектонических (сейсмотектонических) подвижек. Существование первого события доказано за счет присутствия в разрезе маркирующего брекчированного горизонта в толще гиттии [Nikolaeva et al., $2016 a, 2017]$. Второе событие предполагается на основе зафиксированных методом георадиолокации нарушений согласного залегания маркирующего слоя и синформного смещения подстилающего минерального основания, а также наличия сейсмообвалов в толще гиттии, которые залегают над этим слоем. Подтверждением предложенной версии являются и обнаруженные независимыми группами исследователей многочисленные сейсмонарушения скального субстрата и рыхлых отложений в ближайших окрестностях - на побережьях Имандры и в Хибинах [Zykov, 2001; Shvarev, 2003; Maksimov, Tolstobrov, 2015].

\section{6. ЗАКЛЮЧЕНИЕ}

Выполненные исследования показали эффективность метода георадиолокации при изучении донных осадков на акватории малых пресноводных водоемов Кольского полуострова. Этому способствовали низкие показатели проводимости и минерализации воды, что, впрочем, характерно для озер Фенноскандинавского щита. В ходе исследования на радарограммах установлены литологические типы донных отложений, их положение в разрезе и несколько локальных участков, отражающих различные деформации и нарушения, которые представлены вертикальными смещениями слоев по кровле толщи песков и алевритов, с амплитудой смещения от 1.3 до 1.7 м, и подводными оползнями. В формировании этих локальных нарушений в рыхлых осадках большая роль принадлежит сейсмотектоническому фактору. Выделенные сейсмодислокации могут быть следствием активизации разломной зоны северо-западного простирания в голоцене, что подтверждается и данными геологического изучения осадков озера и окружающих обстановок.

Применение комплексного подхода, в котором геофизические данные дополняют и сравниваются с данными детального бурения и литостратиграфического изучения осадков, показало хорошие результаты и согласованность. Величина погрешности определения границ по радарограммам в среднем не превышала 0.2 м, что сравнимо с вертикальной разрешающей способностью используемого антенного блока. Большая плотность профилей георадиолокации позволила построить подробные батиметрические карты, а также модель изоповерхности кровли донных осадков водоема, которая позволяет предполагать существование ступенчатых тектонических нарушений.

Таким образом, на основе проведенных работ показано, что георадиолокацию можно применять 
A.I. Rodionov et al.: Evaluation of GPR capabilities in the study of seismogenic faulting and deformation in the bottom sediments...

как рекогносцировочный метод для исследования стратиграфии донных отложений пресноводных водоемов. Получение протяженных профилей с высокой плотностью съемки обеспечивает картирование структуры залегания осадков и взаиморасположение границ пород и фаций. Такие данные позволяют на новом уровне исследовать морфологию дна и минерального основания водоема, мощность и внутреннее строение отдельных слоев, а в контексте задач палеосейсмологии выявлять в них даже малоразмерные деформации и нарушения, которые могут служить маркерами ранее неизвестных геодинамических процессов.

\section{7. БЛАГОДАРНОСТИ}

Работа выполнена при поддержке РФФИ, проект № 17-35-50079 «Поиск и локализация нарушений и деформаций в четвертичных отложениях восточной части Фенноскандинавского щита методом георадиолокации».

\section{8. ЛИТЕРАTУРA / REFERENCES}

Bayer P., Huggenberger P., Renard P., Comunian A., 2011. Three-dimensional high resolution fluvio-glacial aquifer analog: Part 1: Field. Journal of Hydrology 405 (1-2), 1-9. https://doi.org/10.1016/j.jhydrol.2011.03.038.

Bubeck A., Wilkinson M., Roberts G.P., Cowie P.A., McCaffrey K.J.W., Phillips R., Sammonds P., 2015. The tectonic geomorphology of bedrock scarps on active normal faults in the Italian Apennines mapped using combined ground penetrating radar and terrestrial laser scanning. Geomorphology 237, 38-51. https://doi.org/10.1016/j.geomorph. 2014.03.011.

Busby J.P., Merritt J.W., 1999. Quaternary deformation mapping with ground penetrating radar. Journal of Applied Geophysics 41 (1), 75-91. https://doi.org/10.1016/S0926-9851(98)00050-0.

Christie M., Tsoflias G.P., Stockli D.F., Black R., 2009. Assessing fault displacement and off-fault deformation in an extensional tectonic setting using 3-D ground-penetrating radar imaging. Journal of Applied Geophysics 68 (1), 9-16. https://doi.org/10.1016/j.jappgeo.2008.10.013.

Daniels D.J., 2004. Ground Penetrating Radar. MPG Books Limited, Cornwall, 722 p.

Dentith M., O'Neill A., Clark D., 2010. Ground penetrating radar as a means of studying palaeofault scarps in a deeply weathered terrain, southwestern Western Australia. Journal of Applied Geophysics 72 (2), 92-101. https://doi.org/ 10.1016/j.jappgeo.2010.07.005.

Ercoli M., Pauselli C., Frigeri A., Forte E., Federico C., 2013. Geophysical paleoseismology through high resolution GPR data: A case of shallow faulting imaging in Central Italy. Journal of Applied Geophysics 90, 27-40. https://doi.org/ 10.1016/j.jappgeo.2012.12.001.

Ercoli M., Pauselli C., Frigeri A., Forte E., Federico C., 2014. 3-D GPR data analysis for high-resolution imaging of shallow subsurface faults: the Mt Vettore case study (Central Apennines, Italy). Geophysical Journal International 198 (1), 609-621. https://doi.org/10.1093/gji/ggu156.

Evzerov V.Ya., Nikolaeva S.B., 2000. Belts of marginal glacial formations of the Kola region. Geomorfologiya (Geomorphology) (1), 61-73 (in Russian) [Евзеров В.Я., Николаева С.Б. Пояса краевых ледниковых образований Кольского региона // Геоморфология. 2000. № 1. С. 61-73].

Fisher T.G., Jol H.M., Smith D.G., 1995. Ground-penetrating used to assess aggregate in catastrophic flood deposits, northeast Alberta, Canada. Canadian Geotechnical Journal 32 (5), 871-879. https://doi.org/10.1139/t95-083.

Gross R., Green A., Horstmeyer H., Holliger K., 2003. 3-D Georadar images of an active fault: efficient data acquisition, processing and interpretation strategies. Subsurface Sensing Technologies and Applications 4 (1), 19-40. https:// doi.org/10.1023/A:1023059329899.

Jakobsen P.R., Overgaard T., 2002. Georadar facies and glaciotectonic structures in ice marginal deposits, northwest Zealand, Denmark. Quaternary Science Reviews 21 (8-9), 917-927. https://doi.org/10.1016/S0277-3791(01) 00045-2.

Jol H., 2009. Ground Penetrating Radar Theory and Applications. Elsevier, Amsterdam, 544 p.

Kovacs A., 1991. Impulse Radar Bathymetric Profiling in Weed-infested Fresh Water. U.S. Army Corps of Engineers, $19 \mathrm{p}$.

Lagerbäck R., 1990. Late Quaternary faulting and paleoseismicity in northern Fennoscandia, with particular reference to the Lansjärv area, northern Sweden. Geologiska Föreningen i Stockholm Förhandlingar 112 (4), 333-354. https://doi.org/10.1080/11035899009452733.

Last W.M., Smol J.P. (Eds.), 2001. Tracking Environmental Change Using Lake Sediments. Volume 1: Basin Analysis, Coring, and Chronological Techniques. Kluwer Academic Publishers, Dordrecht, 548 p. https://doi.org/10.1007/ 0-306-47669-X.

Lukashov A.D., 1995. Paleoseismotectonics in the Northern Part of Lake Onega. Geological Survey of Finland, Nuclear Waste Disposal Research. Report Yst-90. Espoo, 36 p. 
Lukashov A., Rukosuev S., 1997. The role of glaciotectonics in the formation of drumlins in Russian Karelia. In: R. Kujansuu, M. Saarnisto (Eds.), Contribution to the origin of Quaternary deposits and their resources in Finland and the northwestern part of the Russian Federation. Geological Survey of Finland, Special Paper, vol. 24, p. 51-55.

Lunina O.V., Andreev A.V., Gladkov A.S., 2015. The $1950 M_{\mathrm{w}}=6.9$ Mondy earthquake in southern East Siberia and associated deformations: facts and uncertainties. Journal of Seismology 19 (1), 171-189. https://doi.org/10.1007/ s10950-014-9457-9.

Lunina O.V., Gladkov A.S., Gladkov A.A., Denisenko I.A., 2018. Srednekedrovaya paleoseismodislocation in the Baikal ridge: its structure and throws estimated from ground-penetrating radar data. Geodynamics \& Tectonophysics 9 (2), 531-555 (in Russian) [Лунина О.В., Гладков А.С., Гладков А.А., Денисенко И.А. Среднекедровая палеосейсмодислокация в Байкальском хребте: структура и оценка смещений по данным георадиолокации // Геодинамика и тектонофизика. 2018. Т. 9. № 2. C. 531-555]. https://doi.org/10.5800/GT-2018-9-2-0360.

Maksimov D.A., Tolstobrov D.S., 2015. Georadar sounding in the complex of geological studies of the sedimentary deposits of the White Sea geoblock. In: Geotechnology and mineral processing. Materials of the $6^{\text {th }}$ School of Young Scientists. Kola SC RAS, Apatity, p. 56-59 (in Russian) [Максимов Д.А., Толстобров Д.С. Георадарное зондирование в комплексе геологических исследований осадочных отложений Беломорского геоблока // Геотехнология и обогащение полезных ископаемых: Материалы VI Школы молодых ученых. Апатиты: КНЦ РАН, 2015. С. 56-59].

Malovichko A.A., Sharov N.V., Shchukina Yu.K. ( Eds.), 2007. Earthquakes and Microseismicity in the Problems of Modern Geodynamics of the East European Platform. Book 1. Earthquakes. Publishing House of KarRC RAS, Petrozavodsk, 381 p. (in Russian) [Землетрясения и микросейсмичность в задачах современной геодинамики Восточно-Европейской платформы. Книга 1. Землетрясения / Ред. А.А. Маловичко, Н.В. Шаров, Ю.К. Щукина. Петрозаводск: Изд-во КарНЦ РАН, 2007. 381 с.].

McCalpin J.P. (Ed.), 2009. Paleoseismology. 2nd edition. Academic Press, New York, 629 p.

McClymont A.F., Green A.G., Kaiser A., Horstmeyer H., Langridge R., 2010. Shallow fault segmentation of the Alpine fault zone, New Zealand revealed from 2- and 3-D GPR surveying. Journal of Applied Geophysics 70 (4), 343-354. https://doi.org/10.1016/j.jappgeo.2009.08.003.

McClymont A.F., Green A.G., Villamor P., Horstmeyer H., Grass C., Nobes D.C., 2008. Characterization of the shallow structures of active fault zones using 3-D ground-penetrating radar data. Journal of Geophysical Research: Solid Earth 113 (B10), B10315. https://doi.org/10.1029/2007JB005402.

Meyers R.A., Derald G., Harry M.J., Peterson C., Smith D., 1996. Evidence for eight great earthquake-subsidence events detected with ground-penetrating radar, Willapa barrier, Washington. Geology 24 (2), 99-102. https://doi.org/ 10.1130/0091-7613(1996)024<0099:EFEGES>2.3.CO;2.

Mitrofanov F.P. (Ed.), 2001. Geological Map of the Kola Region. Scale 1:1000000. Publishing House of the Kola SC RAS, Apatity (in Russian) [Геологическая карта Кольского региона. Масштаб 1:1000000 / Ред. Ф.П. Митрофанов. Апатиты: Изд-во КНЦ РАН, 2001].

Mörner N.A., 2004. Active faults and paleoseismicity in Fennoscandia, especially Sweden. Primary structures and secondary effects. Tectonophysics 380 (3-4), 139-157. https://doi.org/10.1016/j.tecto.2003.09.018.

Neal A., 2004. Ground-penetrating radar and its use in sedimentology: principles, problems and progress. EarthScience Reviews 66 (3-4), 261-330. https://doi.org/10.1016/j.earscirev.2004.01.004.

Nikolaeva S.B., 2001. Paleoseismic features in the northeastern part of the Baltic Shield, and their geological and tectonic positions. Geomorfologiya (Geomorphology) (4), 66-74 (in Russian) [Николаева С.Б. Палеосейсмические проявления в северо-восточной части Балтийского щита и их геолого-тектоническая позиция // Геоморфология. 2001. № 4. С. 66-74].

Nikolaeva S.B., Lavrova N.B., Denisov D.B., 2017. A catastrophic Holocene event in the lake bottom sediments of the Kola Region (Northeastern Fennoscandian Shield). Doklady Earth Sciences 473 (1), 308-312. https://doi.org/ 10.1134/S1028334X17030072.

Nikolaeva S.B., Lavrova N.B., Denisov D.B., Tolstobrov D.S., 2016a. Traces of catastrophic processes in the lake bottom sediments at the western coast of the Babinskaya Imandra Lake (Kola region). Bulletin of the Russian Geographical Society 148 (4), 38-52 (in Russian) [Николаева С.Б., Лаврова Н.Б., Денисов Д.Б., Толстобров Д.С. Следы катастрофических процессов в донных осадках озер западного побережья озера Бабинская Имандра (Кольский регион) // Известия Русского географического общества. 2016. Т. 148. № 4. С. 38-52].

Nikolaeva S.B., Nikonov A.A., Shvarev S.V., Rodkin M.V., 2016b. Comprehensive paleoseismic geological studies in a key site in Southwestern Kola Peninsula (northeast of the Fennoscandian Shield). Doklady Earth Sciences 469 (1), 656-660. https://doi.org/10.1134/S1028334X16070138.

Omelyanenko A.V., Khristoforov I.I., 2012. Features of the GPR survey of the watered medium. Mining Informational and Analytical Bulletin (9), 127-132 (in Russian) [Омельяненко А.В., Христофоров И.И. Особенности георадиолокации обводнённых сред // Горный информационно-аналитический бюллетень. 2012. № 9. С. 127-132].

Overgaard T., Jakobsen P.R., 2001. Mapping of glaciotectonic deformation in an ice marginal environment with ground penetrating radar. Journal of Applied Geophysics 47 (3-4), 191-197. https://doi.org/10.1016/S09269851(01)00064-7. 
Pasanen A., 2009. Radar stratigraphy of the glaciotectonically deformed deposits in the Isoniemi area, Haukipudas, Finland. Bulletin of the Geological Society of Finland 81 (1-2), 39-51. https://doi.org/10.17741/bgsf/81.1.002.

Reicherter K.R., Reiss S., 2001. The Carboneras Fault Zone (southeastern Spain) revisited with Ground Penetrating Radar - Quaternary structural styles from high-resolution images. Netherlands Journal of Geosciences - Geologie en Mijnbouw 80 (3-4), 129-138. https://doi.org/10.1017/S0016774600023799.

Sambuelli L., Bava S., 2012. Case study: A GPR survey on a morainic lake in northern Italy for bathymetry, water volume and sediment characterization. Journal of Applied Geophysics 81, 48-56. https://doi.org/10.1016/j.jappgeo. 2011.09.016.

Sambuelli L., Calzoni C., Pesenti M., 2009. Waterborne GPR survey for estimating bottom-sediment variability: A survey on the Po River, Turin, Italy. Geophysics 74 (4), B95-B102. https://doi.org/10.1190/1.3119262.

Schwamborn G.J., Dix J.K., Bull J.M., Rachold V., 2002. High-resolution seismic and ground penetrating radar-geophysical profiling of a thermokarst lake in the western Lena delta, northern Siberia. Permafrost and Periglacial Processes 13 (4), 259-269. https://doi.org/10.1002/ppp.430.

Shalaeva N.V., Starovoitov A.V., 2010. Fundamentals of Seismic Acoustics in Shallow Waters. Manual. Publishing House of the Moscow State University, Moscow, 256 p. (in Russian] [Шалаева Н.В., Старовойтов А.В. Основы сейсмоакустики на мелководных акваториях. Учебное пособие. М.: Изд-во МГУ, 2010. 256 с.].

Shitov M.V., Biske G.S., Sumareva I.V., 2010. Late Holocene seismic event in the Southeastern Priladozhie. II. Parameters. Bulletin of Saint Petersburg University. Series 7: Geology, Geography (3), 18-28 (in Russian) [Шитов M.В., Бискэ Г.С., Сумарева И.В. Позднеголоценовое сейсмическое событие в Юго-Восточном Приладожье. II. Параметры // Вестник Санкт-Петербургского университета. Серия 7: геология, география. 2010. № 3. C. 18-28].

Shvarev S.V., 2003. Post-glaciation tectonic movements and the occurrence of the terraces of Lake Imandra (Kola Peninsula). Geomorfologiya (Geomorphology) (4), 97-104 (in Russian) [Шварев C.В. Послеледниковые тектонические движения и формирование террас озера Имандра (Кольский полуостров) // Геоморфология. 2003. № 4. С. 97-104].

Smith C.A., Nyberg J., Bergman B., 2017. Comparison between hydroacoustical and terrestrial evidence of glacially induced faulting, Lake Voxsjon, Central Sweden. International Journal of Earth Sciences 107 (1), 169-175. https:// doi.org/10.1007/s00531-017-1479-4.

Starovoitov A.V., 2008. Interpretation of GPR data. Manual. Publishing House of the Moscow State University, Moscow, 192 p. (in Russian) [Старовойтов А.В. Интерпретация георадиолокационных данных. Учебное пособие. М.: Изд-во МГУ, 2008. 192 с.].

Starovoytov A.V., Tokarev M.Yu., Marchenko A.L., Subetto D.A., Rybalko A.E., Aleshin M.I., 2016. GPR potential when investigating quaternary deposits in lakes of Karelia // Transactions of Karelian Research Centre of RAS, Series Limnology, Oceanology (5), 62-75 (in Russian) [Старовойтов А.В., Токарев М.Ю., Марченко А.Л., Субетто Д.А., Рыбалко А.Е., Алешин М.И. Возможности георадиолокации при изучении четвертичных отложений // Труды Карельского научного центра РАН. Серия Лимнология. Океанология. 2016. № 5. C. 62-75]. https://doi.org/ 10.17076/lim268.

Tamura T., Murakami F., Nanayama F., Watanabe K., SaitoY., 2008. Ground-penetrating radar profiles of Holocene raised-beach deposits in the Kujukuri strand plain, Pacific coast of Eastern Japan. Marine Geology 248 (1-2), 11-27. https://doi.org/10.1016/j.margeo.2007.10.002.

Taraban'ko A.V., 2007. Application of the GPR for the study of seismic rupture generated during shallow intraplate earthquakes. Bulletin of Kamchatka Regional Association Educational-Scientific Center. Earth Sciences (1), 154-158 (in Russian) [Тарабанько A.B. Применение георадиолокации при изучении разрывных нарушений, связанных с коровыми землетрясениями в районе реки Поперечная (Южная Камчатка) // Вестник КРАУНЦ. Науки о Земле. 2007. № 1. С. 154-158].

Tronicke J., Villamor P., Green A.G., 2006. Detailed shallow geometry and vertical displacement estimates of the Maleme Fault Zone, New Zealand, using 2D and 3D georadar. Near Surface Geophysics 4 (3), 155-161. https://doi.org/ 10.3997/1873-0604.2005041.

Vladov M.L., Pyatilova A.M., 2009. Influence of the water layer upon the depth of ground radar investigations in freshwater reservoirs. Moscow University Geology Bulletin 64 (1), 59-62. https://doi.org/10.3103/S01458752090 10098.

Vladov M.L., Starovoitov A.V., 2004. Introduction to GPR. Manual. Publishing House of the Moscow State University, Moscow, 153 p. (in Russian) [Владов М.Л., Старовойтов А.В. Введение в георадиолокацию. Учебное пособие. М.: Изд-во МГУ, 2004. 153 с.].

Weill P., Tessier B., Mouaze D., Bonnot-Courtois C., Norgeot C., 2012. Shelly cheniers on a macrotidal flat (MontSaintMichel bay, France) - internal architecture revealed by ground-penetrating radar. Sedimentary Geology 279, 173-186. https://doi.org/10.1016/j.sedgeo.2010.12.002.

Zykov D.S., 2001. Modern Geodynamics of the North Karelia Zone (Baltic Shield). GEOS, Moscow, 146 p. (in Russian) [Зыков Д.С. Новейшая геодинамика Северо-Карельской зоны (Балтийский щит). М.: ГЕОС, 2001. 146 с.]. 


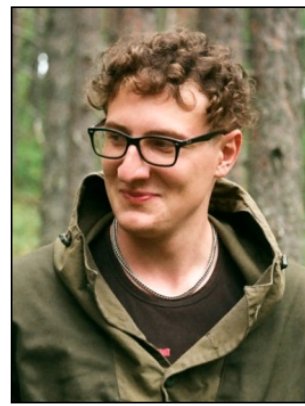

Александр Игоревич Родионов, аспирант, м.н.с.

Институт геологии КарНЦ РАН

185910, Петрозаводск, ул. Пушкинская, 11, Россия

$\triangle$ e-mail: fabian4695@gmail.com

ORCID ID https://orcid.org/0000-0003-1006-051X

Aleksander I. Rodionov, Post-Graduate Student, Junior Researcher

Institute of Geology, Karelian Research Center of RAS

11 Pushkinskaya street, Petrozavodsk 185910, Russia

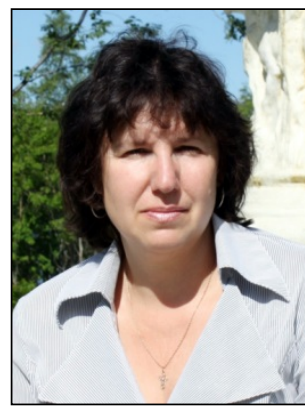

Светлана Борисовна Николаева, канд. геол.-мин. наук, с.н.с.

Геологический институт КНЦ РАН

184209, Апатиты, ул. Ферсмана, 14, Россия

e-mail: nikolaeva@geoksc.apatity.ru

ORCID ID https://orcid.org/0000-0002-6658-0496

Svetlana B. Nikolaeva, Candidate of Geology and Mineralogy, Senior Researcher Geological Institute, Kola Science Centre of RAS

14 Fersman Street, Apatity 184209, Russia

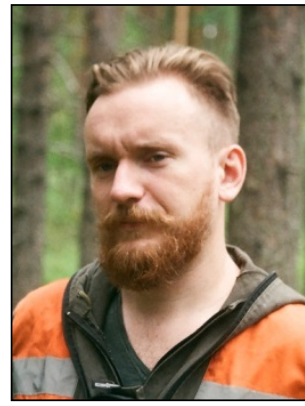

Павел Александрович Рязанцев, канд. геол.-мин. наук, с.н.с.

Институт геологии КарНЦ РАН

185910, Петрозаводск, ул. Пушкинская, 11, Россия

e-mail: chthonian@yandex.ru

ORCID ID https://orcid.org/0000-0002-1944-9479

Pavel A. Ryazantsev, Candidate of Geology and Mineralogy, Senior Researcher Institute of Geology, Karelian Research Center of RAS

11 Pushkinskaya street, Petrozavodsk 185910, Russia 